H A R VAR D

\title{
Goals Gone Wild: The Systematic Side Effects of Over-Prescribing Goal Setting
}

Lisa D. Ordóñez

Maurice E. Schweitzer

Adam D. Galinsky

Max H. Bazerman

\section{Working Paper}

09-083 
Goals Gone Wild: The Systematic Side Effects of Over-Prescribing Goal Setting

\author{
Lisa D. Ordóñez \\ Eller College of Management, University of Arizona
}

Maurice E. Schweitzer

Wharton School, University of Pennsylvania

Adam D. Galinsky

Kellogg School of Management, Northwestern University

Max H. Bazerman

Harvard Business School, Harvard University 


\begin{abstract}
Goal setting is one of the most replicated and influential paradigms in the management literature. Hundreds of studies conducted in numerous countries and contexts have consistently demonstrated that setting specific, challenging goals can powerfully drive behavior and boost performance. Advocates of goal setting have had a substantial impact on research, management education, and management practice. In this article, we argue that the beneficial effects of goal setting have been overstated and that systematic harm caused by goal setting has been largely ignored. We identify specific side effects associated with goal setting, including a narrow focus that neglects non-goal areas, a rise in unethical behavior, distorted risk preferences, corrosion of organizational culture, and reduced intrinsic motivation. Rather than dispensing goal setting as a benign, over-the-counter treatment for motivation, managers and scholars need to conceptualize goal setting as a prescription-strength medication that requires careful dosing, consideration of harmful side effects, and close supervision. We offer a warning label to accompany the practice of setting goals.
\end{abstract}


Goals Gone Wild: The Systematic Side Effects of Over-Prescribing Goal Setting

For decades, goal setting has been promoted as a halcyon pill for improving employee motivation and performance in organizations. Across hundreds of experiments, dozens of tasks, and thousands of participants across four continents, the results are clear (Locke, Latham, Smith, \& Wood, 1990). Compared to vague, easy goals (e.g., “Do your best”), specific, challenging goals boost performance. In a review of four decades of goal-setting research, Locke and Latham (2006) claim, "So long as a person is committed to the goal, has the requisite ability to attain it, and does not have conflicting goals, there is a positive, linear relationship between goal difficulty and task performance.”

In this article, however, we contend that goal setting has been over-prescribed. In particular, we argue that goal setting has powerful and predictable side effects. Rather than being offered as an “over-the-counter” salve for boosting performance, goal setting should be prescribed selectively, presented with a warning label, and closely monitored.

\section{Emblematic Examples of Goals Gone Wild}

Here are just a few examples of the hazards of indiscriminate goal setting. First, consider Sears, Roebuck and Co.’s experience with goal setting in the early 1990s. Sears set sales goals for its auto repair staff of $\$ 147 /$ hour. This specific, challenging goal prompted staff to overcharge for work and to complete unnecessary repairs on a companywide basis (Dishneau, 1992). Ultimately, Sears’ Chairman Edward Brennan acknowledged that goal setting had motivated Sears' employees to deceive customers. Sears' "goal setting process for service advisers created an environment where mistakes did occur,” Brennan admitted (Santoro \& Paine, 1993). 
In the late 1990s, specific, challenging goals fueled energy-trading company Enron’s rapid financial success. Ackman (2002) compares Enron’s incentive system to “paying a salesman a commission based on the volume of sales and letting him set the price of goods sold.” Even during Enron's final days, Enron executives were rewarded with large bonuses for meeting specific revenue goals. In sum, "Enron executives were meeting their goals, but they were the wrong goals," according to employee compensation expert Solange Charas. By focusing on revenue rather than profit, Enron executives drove the company into the ground.

In the late 1960s, the Ford Motor Company was losing market share to foreign competitors that were selling small, fuel-efficient cars. CEO Lee Iacocca announced the specific, challenging goal of producing a new car that would be "under 2000 pounds and under \$2,000" and would be available for purchase in 1970. This goal, coupled with a tight deadline, meant that many levels of management signed off on unperformed safety checks to expedite the development of the car-the Ford Pinto. One omitted safety check concerned the fuel tank, which was located behind the real axle in less than 10 inches of crush space. Lawsuits later revealed what Ford should have corrected in its design process: the Pinto could ignite upon impact. Investigations revealed that after Ford finally discovered the hazard, executives remained committed to their goal and instead of repairing the faulty design, calculated that the costs of lawsuits associated with Pinto fires (which involved 53 deaths and many injuries) would be less than the cost of fixing the design. In this case, the specific, challenging goals were met (speed to market, fuel efficiency, and cost) at the expense of other important features that were not specified (safety, ethical behavior, and company reputation).

As these disasters suggest, the harmful effects of goal setting have received far too little attention in the management literature. Although prior work has acknowledged "pitfalls" of goal 
setting (Latham \& Locke, 2006), we argue that the harmful side effects of goal setting are far more serious and systematic than prior work has acknowledged. First, we begin by describing the systematic and predictable ways in which goal setting harms organizations. We describe how the use of goal setting can degrade employee performance, shift focus away from important but nonspecified goals, harm interpersonal relationships, corrode organizational culture, and motivate risky and unethical behaviors. We argue that, in many situations, the damaging effects of goal setting outweigh its benefits.

Second, we offer a warning label to guide the use of goal setting. We identify specific questions managers should ask to ascertain whether the harmful effects of goal setting outweigh the potential benefits.

Third, we call for further study of the adverse consequences of goal setting. Given the widespread endorsement and use of goal setting, we argue that the harmful effects of goal setting deserve additional scholarly and managerial attention.

\section{How Goals Go Wild}

Advocates of goal setting argue that for goals to be successful, they should be specific and challenging. Countless studies (see Locke \& Latham, 2002, 2006) find that specific, challenging goals motivate performance far better than "do your best” exhortations. According to these findings, specific goals provide clear, unambiguous, and objective means for evaluating employee performance. Specific goals focus people’s attention; lacking a specific goal, employee attention may be dispersed across too many possible objectives. In turn, because challenging goals, or “stretch” goals, create a discrepancy between one’s current and expected output, they motivate greater effort and persistence. 
Although specific, challenging goals can produce positive results, we argue that it is often these same characteristics of goals that cause them to "go wild." When Goals Are Too Specific

As research has shown, goals focus attention. Unfortunately, goals can focus attention so narrowly that people overlook other important features of a task. Consider Simons and Chabris' (1999; Neisser, 1979) well-known study of inattentional blindness. The researchers asked participants to watch a video in which two groups of players pass basketballs. One group wears white shirts; the other group wears dark shirts. Given the task of counting basketball passes among people wearing only white shirts, people unconsciously block out the black shirted individuals. As a result of this narrow focus, most participants fail to notice when a man wearing a black gorilla suit saunters into the middle of the screen, pounds his chest, and walks off screen. Intense concentration on the counting task causes people to overlook a striking element of their visual world. This focusing problem has broad application (Bazerman \& Chugh, 2006) and direct relevance to goal setting.

Narrow Goals. With goals, people narrow their focus. This intense focus can blind people to important issues that appear unrelated to their goal (as in the case of Ford employees who overlooked safety testing to rush the Pinto to market). The tendency to focus too narrowly on goals is compounded when managers chart the wrong course by setting the wrong goal (e.g., setting revenue rather than profit goals at Enron).

Setting appropriate goals is a difficult, intricate process. Suppose that a university department bases tenure decisions primarily on the number of articles that professors publish. This goal will motivate professors to accomplish the narrow objective of publishing articles. Other important objectives, however, such as research impact, teaching, and service, may suffer. 
Consistent with the classic notion that you get what you reward (Kerr, 1975, 1995), goal setting may cause people to ignore important dimensions of performance that are not specified by the goal setting system.

Staw and Boettger (1990) document the hazards of narrow focus fostered by goals in a clever study. They asked students to proofread a paragraph that contained both grammatical and blatant content errors. The paragraph was purportedly going to be used in a brochure promoting the business college. The authors found that individuals instructed to "do your best" were more likely to correct both grammatical and content errors than were those who were given explicit goals to correct either grammar or content. Tenbrunsel, Wade-Benzoni, Messick, and Bazerman (2000) make a related point. They argue that standards, such as the Environmental Protection Agency's standards on pollution, too often focus compliance on specific, measureable standards at the expense of the overall goal of protecting the environment.

When manager set targets for specific dimensions of a problem, they often fail to anticipate the broader results of their directives. Goals "inform the individual about what behavior is valued and appropriate” (Staw \& Boettger, 1990). The very presence of goals may lead employees to focus myopically on short-term gains and to lose sight of the potential devastating long-term effects on the organization.

Too many goals. A related problem occurs when employees pursue multiple goals at one time. Shah, Friedman, and Kruglanski (2002) demonstrate that individuals with multiple goals are prone to concentrate on only one goal. Related research suggests that some types of goals are more likely to be ignored than others. In a stock selection task, Gilliland and Landis (1992) gave participants both quality goals and quantity goals. When quantity and quality goals were both difficult, participants sacrificed quality to meet the quantity goals. Goals that are easier to 
achieve and measure (such as quantity) may be given more attention than other goals (such as quality) in a multi-goal situation.

Inappropriate Time Horizon. Even if goals are set on the right attribute, the time horizon may be inappropriate. For example, goals that emphasize immediate performance (e.g., this quarter's profits) prompt managers to engage in myopic, short-term behavior that harms the organization in the long run. Cheng, Subramanyam, and Zhang (2005) showed that firms that frequently issue quarterly earnings reports, compared to firms that report earnings less frequently, tended to meet or beat analyst expectations, but also tended to invest less in research and development. The effort to meet short-term targets occurred at the expense of long-term growth. Some companies are learning from these mistakes; Coca Cola announced in 2002 that is would cease issuing quarterly earnings guidance and provide more information about progress on meeting long-term objectives.

The time horizon problem is related to the notion that goals can lead people to perceive their goals as ceilings rather than floors for performance. Just as the pigeons in the Skinner experiments demonstrated “post-pellet pause” (a state of inactivity after their pecking produced the desired pellet of food), once a goal is achieved people relax, rest, and pause. For example, a salesperson, after meeting her monthly sales quota, may spend the rest of the month playing golf rather than working on new sales leads. An excellent example of this problem comes from a study of New York City cab drivers. This study answers the age-old question of why it is so hard to get a cab on a rainy day (Camerer, Babcock, Loewenstein, \& Thaler, 1997). Most people blame demand: When it is raining, more people hail cabs than when the weather is clear. But as it turns out, supply is another important culprit. As a day progresses, cabs start disappearing more quickly from Manhattan streets on rainy days than on sunny days. Why? Because of the 
specific, daily goals that most cab drivers set: a goal to earn double the amount it costs them to rent out their cabs for a 12-hour shift. On rainy days, cabbies make money more quickly than on sunny days (because demand is indeed higher), hit their daily goal sooner, and then they go home (the problem of goals as ceilings). This finding flies in the face of the economic tenet of wage elasticity, which predicts that people should work more hours on days when they can earn more money and less on days when they earn less. If NYC taxi drivers used a longer time horizon (perhaps weekly or monthly), kept track of indicators of increased demand (e.g., rain or special events), and ignored their typical daily goal, they could increase their overall wages, decrease the overall time they spend working, and improve the welfare of drenched New Yorkers. When Goals Are Too Challenging

Proponents of goal setting claim that a positive linear relationship exists between the difficulty of a goal and employee performance. Specifically, they argue that goals should be set at the most challenging level possible to inspire effort, commitment, and performance- - but not so challenging that employees see no point in trying. This logic makes intuitive sense, yet stretch goals also cause serious side-effects: shifting risk attitudes, promoting unethical behavior, and triggering the psychological costs of goal failure.

Risk taking. As prior work conjectured (Neale \& Bazerman, 1985; Knight, Durham, \& Locke, 2001) and recent work demonstrates (Larrick, Heath, \& Wu, in press), goal-setting distorts risk preferences. Larrick et al. (in press) demonstrate that people motivated by specific, challenging goals adopt riskier strategies and choose riskier gambles than do those with less challenging or vague goals.

Related work has found that goals harm negotiation performance by increasing risky behavior. Negotiators with goals are more likely to reach an inefficient impasse than are 
negotiators who lack goals (Neale \& Bazerman, 1985; Galinsky, Mussweiler, \& Medvec, 2002). For example, Galinsky et al. (2002) found that stretch goals increased the number of impasses, and Larrick et al. (in press) found that goals prompted participants to make larger demands that in turn destroyed value. It is also quite easy to imagine that in a very different context, a negotiator who has obtained concessions sufficient to reach their goal, will satisfice and accept the agreement on the table, even if the value maximizing strategy would be to continue the negotiation process. Clearly, in some domains, goal setting can significantly harm performance rather than promoting better outcomes.

An excessive focus on goals may have prompted the risk-taking behavior that lies at the root of many real-world disasters. The collapse of Continental Illinois Bank provides an example with striking parallels to the collapse of Enron and the financial crisis of 2008. In 1976, Continental's chairman announced that within five years, the magnitude of the bank's lending would match that of any other bank. To reach this stretch goal, the bank shifted its strategy from conservative corporate financing toward aggressive pursuit of borrowers. Continental allowed officers to buy loans made by smaller banks that had invested heavily in very risky loans. Continental would have become the seventh-largest U.S. bank if its borrowers had been able to repay their loans; instead, following massive loan defaults, the government had to bail out the bank.

In other domains, such as the design process for the Ford Pinto, the perceptual blinders of narrow and challenging goals have had fatal consequences. Kayes (2006) cites the 1996 Mt. Everest disaster in which eight climbers died due to the decisions of the two team leaders as an example of “destructive goal pursuit.” On Mt. Everest, world-class high-altitude guides, Rob Hall and Scott Fischer, identified so closely with the goal of reaching the summit that they made 
risky decisions that led to their own and 6 of their clients' deaths. Kayes identifies warning signs of leaders who have become excessively fixated on goals. These occur in leaders who express narrowly defined goals, associate goals with destiny, express an idealized future, offer goaldriven justifications, face public expectations, and attempt to engage in face-saving behavior.

Unethical behavior. Another serious way in which goal setting can damage organizations is by promoting unethical behavior. At Sears' automotive unit, employees charged customers for unnecessary repairs in order to meet specific, challenging goals. In the late 1980s, Miniscribe employees shipped bricks to customers instead of disk drives to meet shipping targets. And in 1993, Bausch and Lomb employees falsified financial statements to meet earnings goals. In each of these cases, specific, challenging goals motivated employees to engage in unethical behavior.

Goal setting has been promoted as a powerful motivational tool, but substantial evidence demonstrates that in addition to motivating constructive effort, goal setting can induce unethical behavior. Surprisingly little research in the goal-setting literature has examined what people might do when they have the opportunity to misrepresent their performance or cheat to attain a goal. One of the few studies that looked for a direct link between goal setting and cheating found that participants were more likely to misrepresent their performance level when they had a specific, challenging goal than when they did not, especially when their actual performance level fell just short of reaching the goal (Schweitzer, Ordóñez, \& Douma, 2004).

Goal setting can promote two different types of cheating behavior. First, when motivated by a goal, people may choose to use unethical methods to reach it. For example, at Sears, mechanics told customers that they needed unnecessary repairs and then performed and charged them for this unneeded work. Second, goal setting can motivate people to misrepresent their performance level —in other words, to report that they met a goal when in fact they fell short. For 
example, employees at Bausch and Lomb who were driven to reach sales targets reported sales that never took place. Similarly, when senior management gives lawyers and consultants specific, challenging goals for billable hours, they may bill clients for hours they never worked. Goal setting, of course, is not the only cause of employee unethical behavior, but it is certainly an important, understudied ingredient. A number of factors serve as catalysts in the relationship between goal setting and cheating: lax oversight, financial incentives for meeting performance targets (Jensen, 2003; Schweitzer et al., 2004), and organizational cultures with a weak commitment to ethics.

The interplay between organizational culture and goal setting is particularly important. An ethical organizational culture can reign in the harmful effects of goal setting, but at the same time, the use of goals can influence organizational culture. Specifically, the use of goal setting, like “management by objectives,” creates a focus on ends rather than means. Barsky (2007) argues that goal setting impedes ethical decision making by making it harder for employees to recognize ethical issues and easier for them to rationalize unethical behavior. Given that small actions within an organization can have broad implications for organizational culture (Fleming \& Zyglidopoulos, 2008), we postulate that aggressive goal setting within an organization will foster an organizational climate ripe for unethical behavior. That is, not only does goal setting directly motivate unethical behavior, but its introduction may also motivate unethical behavior indirectly by subtly altering an organization's culture. In sum, although many factors contribute to unethical behavior, the point cannot be overstated: goal setting motivates unethical behavior.

Dissatisfaction and the psychological consequences of goal failure. One problem embedded in stretch goals is the possibility that the goal may not be reached. In negotiations, for example, challenging goals can increase negotiation and task performance, but decrease 
satisfaction with high-quality outcomes (Galinsky et al., 2002; Garland, 1983). These decreases in satisfaction influence how people view themselves and have important consequences for future behavior. Mussweiler and Strack (2000) found that giving someone a challenging goal versus an easy goal on an attention task or an intelligence test improved performance, but left people questioning their concentration abilities and overall intelligence. These goal-induced reductions in self-efficacy can be highly detrimental, because perceptions of self-efficacy are a key predictor of task engagement, commitment, and effort (Bandura, 1977).

\section{Goals, Learning, and Cooperation}

In order to adapt to a competitive landscape, organizations need employees who are able to learn and collaborate with their colleagues. Goals can inhibit both learning and cooperation.

Goals inhibit learning. When individuals face a complex task, specific, challenging goals may inhibit learning from experience and degrade performance compared to exhortations to “do your best” (Cervone, Jiwani, \& R. Wood, 1991; Earley, Connolly, \& Ekegren, 1989; Robert Wood, Bandura, \& Bailey, 1990). An individual who is narrowly focused on a performance goal, will be less likely to try alternative methods that could help her learn how to perform a task. As an example of this phenomenon, Locke and Latham (2002) describe an air traffic controller simulation in which the performance goal interfered with learning in this complex domain (Kanfer \& Ackerman, 1989). Overall, the narrow focus of specific goals can inspire performance but prevent learning.

Locke and Latham recommend that "learning goals” should be used in complex situations rather than "performance goals.” In practice, however, managers may have trouble determining when a task is complex enough to warrant a learning, rather than a performance goal. In many changing business environments, perhaps learning goals should be the norm. Even 
when tasks are complex enough to clearly warrant learning goals, managers face the challenge of identifying the specific, challenging goal levels for learning objectives. The goal of setting the right goals is itself a challenging affair.

Goals create a culture of competition. Organizations that rely heavily on goal setting may erode the foundation of cooperation that holds groups together. Arrow (1973) argued that an exclusive focus on profit maximization can harm altruistic and other-regarding behavioral motives. Similarly, being too focused on achieving a specific goal may decrease extra-role behavior, such as helping coworkers (Wright, George, Farnsworth, \& McMahan, 1993). Goals may promote competition rather than cooperation and ultimately lower overall performance (Mitchell \& Silver, 1990).

\section{When Goals Harm Motivation Itself}

As goal setting increases extrinsic motivation, it can harm intrinsic motivation - engaging in a task for its own sake (Mossholder, 1980; Rawsthorne \& Elliot, 1999; Shalley \& Oldham, 1985). This is true of rewards in general (Deci, Koestner, \& Ryan, 1999), but several studies demonstrate that this is particularly true for goals themselves (Elliot \& Harackiewicz, 1996; Rawsthorne \& Elliot, 1999).

This problem is important, because managers are likely to over-value and overuse goals. Although people recognize the importance of intrinsic rewards in motivating themselves, people exaggerate the importance of extrinsic rewards in motivating others (Heath, 1999). In short, managers may think that others need to be motivated by specific, challenging goals far more often than they actually do. 
By setting goals, managers may create a hedonic treadmill in which employees are motivated by external means (goals, rewards, etc.) and not by the intrinsic value of the job itself (Deci, 1971, 1975).

Can We Set the Right Goal? The Problem of Calibration

Proponents of goal setting have long championed the simplicity of its implementation and the efficiency of its effects. In practice, however, setting goals is a challenging process, especially in novel settings.

Goal setting can become problematic when the same goal is applied to many different people. Given the variability of performance on any given task, any standard goal set for a group of people will vary in difficulty for individual members; thus, the goal will simultaneously be too easy for some and too difficult for others. Conversely, idiosyncratically tailoring goals to each individual can lead to charges of unfairness. This has important implications, because employee perceptions of whether rewards fairly match effort and performance can be one of the best predictors of commitment and motivation (Cropanzano, Byrne, Bobocel, \& Rupp, 2001; Walster, Walster, \& Berscheid, 1978). For example, salary disparities between executives and lower-level managers predict the organizational exodus of underpaid managers (Wade, O'Reilly, \& Pollock, 2006). Both broad-based goals and idiosyncratic goals can lead to problems.

Perverse incentives can also make goal setting politically and practically problematic. When reaching pre-set goals matters more than absolute performance, self-interested individuals can strategically set (or guide their managers to set) easy-to-meet goals. By lowering the bar, they procure valuable rewards and accolades. Many company executives often choose to manage expectations rather than maximize earnings (Bartov, Givoly, \& Hayn, 2002). In some cases, managers set a combination of goals that, in aggregate, appears rational, but is in fact not 
constructive. For example, consider a self-interested CEO who receives a bonus for hitting targets. This CEO may set a mix of easy goals (that she is sure to meet) and 'what the hell' difficult goals (that she does not plan to meet). On average, the goal levels may seem appropriate, but this mix of goals may generously reward the CEO (when she meets the easy goals) without motivating any additional effort when the goals are difficult. In reality, CEOs (and many Wall Street executives) face asymmetric rewards-a large bonus for meeting the goal in one year, but no fear of having to return a large bonus the following year for underperforming.

Getting it Right: Harness the Power of Goals

There are many ways in which goals go wild: they can narrow focus, motivate risktaking, lure people into unethical behavior, inhibit learning, increase competition, and decrease intrinsic motivation. At the same time, goals can inspire employees and improve performance. How, then, should we prescribe the use of goal setting? Which systematic side effects of goal setting should we most closely monitor, and how can we minimize the side effects?

Just as doctors prescribe drugs selectively, mindful of interactions and adverse reactions, so too should managers carefully prescribe goals. To do so, managers must consider-and scholars must study — the complex interplay between goal setting and organizational contexts, as well as the need for safeguards and monitoring.

According to General Electric’s Steve Kerr, an expert in reward and measurement systems, “most organizations don’t have a clue how to manage 'stretch goals”” (Sherman, 1995). He advises managers to avoid setting goals that increase employee stress, to refrain from punishing failure, and to provide the tools employees need to meet ambitious goals. Integrating these ideas, we urge managers to think carefully about whether goals are necessary and, if so, 
about how to implement a goal-setting system. In particular, we encourage managers to ask themselves the questions listed in the warning label in Table 1 when considering the use of goals.

\section{\ WARNING}

Goals may cause systematic problems in organizations due to narrowed focus, unethical behavior, increased risk taking, decreased cooperation, and decreased intrinsic motivation.

Use care when applying goals in your organization.

This cautious approach to setting goals is consistent with King and Burton's (2003) claim that goals should be used only in the narrowest of circumstances:

The optimally striving individual ought to endeavor to achieve and approach goals that only slightly implicate the self; that are only moderately important, fairly easy, and moderately abstract; that do not conflict with each other; and that concern the accomplishment of something other than financial gain.

After answering the questions in Table 1 and considering this advice, many managers may conclude that goals are not the best way to motivate their employees. At a minimum, we recommend that managers who use goals, do so with great caution.

\section{Directions for Future Research}

Why has prior research largely ignored the harmful effects of setting goals? Part of the problem stems from the methodological prism scholars have used to study goal setting. Most goal setting research, whether it occurs in the lab or in the field, has been conducted in simple, well-specified domains with well-specified performance measures such as the number of 
anagrams completed (e.g., Vance \& Colella, 1990), the amount of electricity used (Becker, 1978), or the number of sales completed (Mann, Samson, \& Dow, 1998).

Although all four authors of this article are enthusiastic supporters of lab research, we argue that goals cause the most harm in complex, natural settings when outcomes are interdependent, monitoring is difficult, and cheating possible.

When scholars have recognized harmful effects of goals, these effects have been characterized as aberrations that could be addressed with simple solutions and relatively little effort. Latham and Locke (2006) list 10 "pitfalls” of goal setting, such as conflict between group members, task complexity, and financial incentives. For each pitfall, the authors suggest simple (and often untested) solutions. For example, noting that dishonest means could be used to earn financial rewards tied to goals, they suggest that an organization establish "control systems," that the CEO should model an ethical culture, and that offending employees "should be fired regardless of any revenue streams they generate or costs they reduce.” Recent corporate ethics scandals suggest that this advice may be difficult to follow. Further, as Barsky's model (2007) of the ethical implications of organizational goal setting implies, ethical infractions are not simply a byproduct of a few "bad apple" employees, but a systematic result of setting specific, challenging goals; similarly, Jensen (2003) contends that lying and cheating are byproducts of connecting rewards to goal achievement.

How did this discrepancy between the goal-setting literature and the wild world of actual organizations develop? We argue that researchers (with the goal of publishing) followed a set of paradigmatic paths that easily provided a practical, replicable set of evidence on goal setting. As Wason (1960) demonstrated long ago, people (including researchers) tend to seek confirmatory evidence and fail to search for disconfirmation. The relatively few studies that have directly 
challenged the conventional wisdom on goal setting (Staw \& Boettger, 1990; Schweitzer et al., 2004) have been systematically ignored in reviews of goal setting authored by goal-setting advocates (e.g., Locke \& Latham, 2006), even when they consider the “pitfalls” of goals.

Like the participants in goal-setting studies themselves, goal-setting advocates have met their specific, challenging goal of becoming publishing juggernauts, at the expense of the broader objectives of providing scientific rigor and sound managerial advice. We advocate a new generation of goal-setting research that correctly identifies broader objectives and carefully balances the inspirational and insidious effects of setting goals.

\section{Conclusion}

For decades, scholars have prescribed goal setting as an all-purpose remedy for employee motivation. Rather than dispensing goal setting as a benign, over-the-counter treatment for students of management, experts need to conceptualize goal setting as a prescription-strength medication that requires careful dosing, consideration of harmful side effects, and close supervision. Given the sway of goal setting on intellectual pursuits in management, we call for a more self-critical and less self-congratulatory approach to the study of goal setting. 


\section{References}

Ackman, D. (2002, March 22). Pay Madness At Enron. Forbes.com. Retrieved December 16, 2008, from http://www.forbes.com/2002/03/22/0322enronpay.html.

Arrow, K. (1973). Social responsibility and economic efficiency. Public Policy, 21, 300-317.

Bandura, A. (1977). Social Learning Theory. New York: General Learning Press.

Barsky, A. (2007). Understanding the ethical cost of organizational goal-setting: A review and theory development. Journal of Business Ethics, 81(1), 63-81.

Bartov, E., Givoly, D., \& Hayn, C. (2002). The rewards to meeting or beating earnings expectations. Journal of Accounting and Economics, 33(2), 173-204.

Bazerman, M. H., \& Chugh, D. (2006). Decisions without blinders. Harvard Business Review, 84(1), 88-97. doi: Article.

Becker, L. J. (1978). Joint effect of feedback and goal setting on performance: A field study of residential energy conservation. Journal of Applied Psychology, 63(4), 428-433.

Camerer, C., Babcock, L., Loewenstein, G., \& Thaler, R. (1997). Labor Supply of New York City Cabdrivers: One Day at a Time. The Quarterly Journal of Economics, 112(2), 407441.

Cervone, D., Jiwani, N., \& Wood, R. (1991). Goal setting and the differential influence of selfregulatory processes on complex decision-making performance. Journal of Personality and Social Psychology, 61(2), 257-66.

Cheng, M., Subramanyam, K. R., \& Zhang, Y. (2005). Earnings Guidance and Managerial Myopia. Working Paper, University of Southern California. 
Cropanzano, R., Byrne, Z. S., Bobocel, D. R., \& Rupp, D. E. (2001). Moral Virtues, Fairness Heuristics, Social Entities, and Other Denizens of Organizational Justice. Journal of Vocational Behavior, 58(2), 164-209.

Deci, E. L. (1971). Effects of externally mediated rewards on intrinsic motivation. Journal of Personality and Social Psychology, 18(1), 105-115.

Deci, E. L. (1975). Intrinsic motivation. New York: Plenum.

Deci, E. L., Koestner, R., \& Ryan, R. M. (1999). A meta-analytic review of experiments examining the effects of extrinsic rewards on intrinsic motivation. Psychological Bulletin, 125(6), 627-668.

Dishneau, D. (1992, June 22). Sears Admits Mistakes, Takes Workers O€ Commission. The Associated Press.

Earley, P. C., Connolly, T., \& Ekegren, G. (1989). Goals, strategy development, and task performance: Some limits on the efficacy of goal setting. Journal of Applied Psychology, 74(1), 24-33.

Elliot, A. J., \& Harackiewicz, J. M. (1996). Approach and avoidance achievement goals and intrinsic motivation: A mediational analysis. Journal of Personality and Social Psychology, 70(3), 461-475.

Fleming, P., \& Zyglidopoulos, S. C. (2008). The Escalation of Deception in Organizations. Journal of Business Ethics, 81(4), 837-850.

Galinsky, A. D., Mussweiler, T., \& Medvec, V. H. (2002). Disconnecting outcomes and evaluations: The role of negotiator focus. Journal of Personality and Social Psychology, 83(5), 1131-1140. 
Garland, H. (1983). Influence of ability, assigned goals, and normative information on personal goals and performance: A challenge to the goal attainability assumption. Journal of Applied Psychology, 68(1), 20-30.

Gilliland, S. W., \& Landis, R. S. (1992). Quality and quantity goals in a complex decision task: Strategies and outcomes. Journal of Applied Psychology, 77(5), 672-681.

Heath, C. (1999). On the Social Psychology of Agency Relationships: Lay Theories of Motivation Overemphasize Extrinsic Incentives, . Organizational Behavior and Human Decision Processes, 78(1), 25-62.

Jensen, M. C. (2003). Paying People to Lie: the Truth about the Budgeting Process. European Financial Management, 9(3), 379-406.

Kanfer, R., \& Ackerman, P. L. (1989). Motivation and cognitive abilities: An integrative/aptitude-treatment interaction approach to skill acquisition. Journal of Applied Psychology, 74(4), 657-690.

Kayes, D. C. (2006). Destructive goal pursuit: The Mount Everest disaster. Basingstoke: Palgrave Macmillan.

Kerr, S. (1975). On the Folly of Rewarding A, While Hoping for B. The Academy of Management Journal, 18(4), 769-783.

Kerr, S. (1995). On the Folly of Rewarding A, while Hoping for B. The Academy of Management Executive (1993), 9(1), 7-14.

King, L. A., \& Burton, C. M. (2003). The hazards of goal pursuit. In Virtue, vice, and personality: The complexity of behavior. (pp. 53-69). Washington, DC US: American Psychological Association. 
Knight, D., Durham, C. C., \& Locke, E. A. (2001). The Relationship of Team Goals, Incentives, and Efficacy to Strategic Risk, Tactical Implementation, and Performance. The Academy of Management Journal, 44(2), 326-338.

Larrick, R. P., Heath, C., \& Wu, G. (1900). Goal-Induced Risk Taking in Negotiation and Decision Making. Social Cognition.

Latham, G. P., \& Locke, E. A. (2006). Enhancing the Benefits and Overcoming the Pitfalls of Goal Setting. Organizational Dynamics, 35(4), 332-340.

Locke, E. A., \& Latham, G. P. (2002). Building a practically useful theory of goal setting and task motivation: A 35-year odyssey. American Psychologist, 57(9), 705-717.

Locke, E. A., \& Latham, G. P. (2006). New Directions in Goal-Setting Theory. Current Directions in Psychological Science, 15(5), 265-268.

Locke, E. A., Latham, G. P., Smith, K. J., \& Wood, R. E. (1990). A Theory of Goal Setting \& Task Performance (p. 544). Prentice Hall College Div.

Mann, L., Samson, D., \& Dow, D. (1998). A Field Experiment on the Effects of Benchmarking and Goal Setting on Company Sales Performance. Journal of Management, 24(1), 73-96.

Mitchell, T. R., \& Silver, W. S. (1990). Individual and group goals when workers are interdependent: Effects on task strategies and performance. Journal of Applied Psychology, 75(2), 185-193.

Mossholder, K. W. (1980). Effects of externally mediated goal setting on intrinsic motivation: A laboratory experiment. Journal of Applied Psychology, 65(2), 202-210.

Mussweiler, T., \& Strack, F. (2000). The 'relative self': Informational and judgmental consequences of comparative self-evaluation. Journal of Personality and Social Psychology, 79(1), 23-38. 
Neale, M. A., \& Bazerman, M. H. (1985). The Effect of Externally Set Goals on Reaching Integrative Agreements in Competitive Markets. Journal of Occupational Behaviour, 6(1), 19-32.

Neisser, U. (1979). The Concept of Intelligence. Intelligence, 3(3), 217-27.

Rawsthorne, L. J., \& Elliot, A. J. (1999). Achievement Goals and Intrinsic Motivation: A MetaAnalytic Review. Personality and Social Psychology Review, 3(4), 326-344.

Santoro, M. A., \& Paine, L. S. (1993). Sears auto centers (Harvard Business School case 9-394010). Boston: Harvard Business School Publishing.

Schweitzer, M. E., Ordóñez, L., \& Douma, B. (2004). Goal Setting as a Motivator of Unethical Behavior. Academy of Management Journal, 47(3), 422-432.

Shah , J. Y., Friedman, R., \& Kruglanski , A. W. (2002). Forgetting all else: on the antecedents and consequences of goal shielding. Journal of Personality and Social Psychology, 83(6), 1261-80.

Shalley, C. E., \& Oldham, G. R. (1985). Effects of Goal Difficulty and Expected External Evaluation on Intrinsic Motivation: A Laboratory Study. The Academy of Management Journal, 28(3), 628-640.

Sherman, S. (1995, November). Stretch goals: The dark side of asking for miracles. Fortune, 132(10), 231.

Simons, D. J., \& Chabris , C. F. (1999). Gorillas in our midst: sustained inattentional blindness for dynamic events. Perception, 28(9), 1059-1074.

Staw, B. M., \& Boettger, R. D. (1990). Task revision: A neglected form of work performance. Academy of Management Journal, 33(3), 534-559. 
Tenbrunsel, A. E., Wade-Benzoni, K. A., Messick, D. M., \& Bazerman, M. H. (2000). Understanding the Influence of Environmental Standards on Judgments and Choices. The Academy of Management Journal, 43(5), 854-866.

Vance, R. J., \& Colella, A. (1990). Effects of two types of feedback on goal acceptance and personal goals. Journal of Applied Psychology, 75(1), 68-76.

Wade, J. B., O'Reilly, C. A., \& Pollock, T. G. (2006). Overpaid CEOs and Underpaid Managers: Fairness and Executive Compensation. Organization Science, 17(5), 527-544.

Walster, E., Walster, G. W., \& Berscheid, E. (1978). Equity Theory and Research. Allyn and Bacon.

Wason, P. C. (1960). On the failure to eliminate hypotheses in a conceptual task. Quarterly Journal of Experimental Psychology, 12, 129-140.

Wood, R., Bandura, A., \& Bailey, T. (1990). Mechanisms governing organizational performance in complex decision-making environments. Organizational Behavior and Human Decision Processes, 46(2), 181-201.

Wright, P. M., George, J. M., Farnsworth, S. R., \& McMahan, G. C. (1993). Productivity and extra-role behavior: The effects of goals and incentives on spontaneous helping. Journal of Applied Psychology, 78(3), 374-381. 
Table 1. A Warning Label for Setting Goals

\section{$\triangle$ WARNING}

\section{Goals may cause systematic problems in organizations due to narrowed focus, unethical behavior, increased risk taking, decreased cooperation, and decreased intrinsic motivation.}

Use care when applying goals in your organization.

1. Are the goals too specific?

Narrow goals can blind people to important aspects of a problem. Be sure that goals are comprehensive and include all of the critical components for firm success (e.g., quantity and quality).

2. Are the goals too challenging?

What will happen if goals are not met? How will individual employees and outcomes be evaluated? Will failure harm motivation and self-efficacy?

Provide skills and training to enable employees to reach goals. Avoid harsh punishment for failure to reach a goal.

3. Who sets the goals?

People will become more committed to goals they help to set. At the same time, people may be tempted to set easy to reach goals.

4. Is the time horizon appropriate?

Be sure that short-term efforts to reach a goal do not harm investment in long-term outcomes. For example, consider eliminating quarterly reports as Coco Cola did.

5. How might goals influence risk taking?

Be sure to articulate acceptable levels of risk.

6. How might goals motivate unethical behavior?

Goals narrow focus, such that employees may be less likely to recognize ethical issues. Goals also induce employees to rationalize their unethical behavior and can corrupt organizational cultures. Multiple safeguards may be necessary to ensure ethical behavior while attaining goals (e.g., leaders as exemplars of ethical behavior, making the costs of cheating far greater than the benefit, strong oversight).

7. Can goals be idiosyncratically tailored for individual abilities and circumstances while preserving fairness? 
Strive to set goals that use common standards and account for individual variation.

8. How will goals influence organizational culture?

If cooperation is essential, consider setting team-based rather than individual goals.

9. Are individuals intrinsically motivated?

Assess intrinsic motivation and recognize that goals can curtail intrinsic motivation.

10. Consider the ultimate goals of the organization and what type of goal (performance or learning) is most appropriate?

In complex, changing environments learning goals may be more effective. 